\title{
A new Mannich base and its transition metal (II) complexes - Synthesis, structural characterization and electrochemical study
}

\author{
N RAMAN*, S ESTHAR and C THANGARAJA \\ Department of Chemistry, VHNSN College, Virudhunagar 626 001, India \\ e-mail: drn_raman@yahoo.co.in
}

MS received 21 July 2003; revised 17 April 2004

\begin{abstract}
A new Mannich base, N-(1-morpholinobenzyl) semicarbazide (MBS), formed by the condensation of morpholine, semicarbazide and benzaldehyde, and its $\mathrm{Cu}(\mathrm{II}), \mathrm{Ni}(\mathrm{II}), \mathrm{Co}(\mathrm{II})$ and $\mathrm{Zn}$ (II) complexes have been synthesized. Their structures have been elucidated on the basis of analytical, magnetic, electrical conductivity and spectral study as well as elemental analyses. The complexes exhibit square-planar geometry. The monomeric and non-electrolytic nature of the complexes is evidenced by their magnetic susceptibility and low conductance data. The electrochemical property of the ligand and its complexes in acetonitrile solution was studied by cyclic voltammetry. The X-band ESR spectra of the $\mathrm{Cu}$ (II) complex in DMSO at 300 and $77 \mathrm{~K}$ were recorded and their salient features are reported.
\end{abstract}

Keywords. Mannich base; N-(1-morpholinobenzyl) semicarbazide; transition metal (II) complexes; spectral study; electrochemical behaviour.

\section{Introduction}

Metal complexes of Mannich bases have been studied $^{1-5}$ extensively in recent years due to the selectivity and sensitivity of the ligands towards various metal ions. To our knowledge, Mannich reaction is a three-component condensation reaction consisting of active hydrogen containing compound, formaldehyde and a secondary amine. ${ }^{6}$ Much work has been done so far on isolation of solid complexes of different aromatic aldehydes or ketones, semicarbazones with transition metals. ${ }^{7,8}$ A search through the literature reveals that no work has been done on the condensation of morpholine, benzaldehyde and semicarbazide. It is well known from the literature that semicarbazide compounds containing the amide moiety have a strong ability to form metal complexes. Therefore, it was thought worthwhile to synthesise some metal complexes of this type of Mannich base and investigate its bonding characteristics. We herein report a new Mannich base, N-(1-morpholinobenzyl) semicarbazide formed by the three-component condensation, containing active hydrogen on nitrogen (morpholine), benzaldehyde and semicarbazide. In this ligand system, dicoordination takes place via the $\mathrm{N}$ and $\mathrm{O}$ of semicarbazide. The proposed structure of the synthesised Mannich base is given in scheme 1 .

\section{Experimental}

All the reagents used for the preparation of the ligand and the complexes were Merck products. Spectroscopic grade solvents were used for the spectral and cyclic voltammetric measurements. The carbon, hydrogen and nitrogen contents in each samples were done at the Regional Sophisticated Instrumentation Centre, Central Drug Research Institute, Lucknow. ${ }^{1} \mathrm{H}-\mathrm{NMR}$ and ${ }^{13} \mathrm{C}-\mathrm{NMR}$ spectra of the samples were measured in DMSO- $d_{6}$ at Madurai Kamaraj University, Madurai. The IR spectra were recorded as $\mathrm{KBr}$ pellets using a Perkin-Elmer 783 spectrophotometer. UV-Vis spectra of the complexes

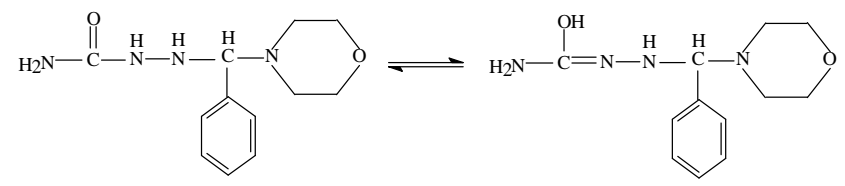

Scheme 1. Structure of the Mannich base ligand. 
were recorded on a Shimadzu UV-1601 spectrophotometer. The X-band ESR spectra of the copper was recorded in DMSO at 300 and $77 \mathrm{~K}$ on a Varian 112 ESR spectrophotometer using tetracyanoethylene (TCNE) as the internal standard at the Regional Sophisticated Instrumentation Centre, Indian Institute of Technology, Mumbai. Magnetic susceptibility measurements of the complexes were done using a Gouy balance. Copper sulphate was used as the calibrant. Cyclic voltammogram of the complexes was recorded in acetonitrile solution at $300 \mathrm{~K}$ using a three-electrode cell comprising reference $\mathrm{Ag} /$ $\mathrm{AgCl}$, auxillary Pt and working glassy carbon electrodes. Molar conductivity was measured on a Systronic conductivity bridge with a dip-type cell, using $10^{-3} \mathrm{M}$ solution of complexes in DMSO. FAB-mass spectrum of the complex was recorded on a JEOL SX 102/DA-6000 mass spectrometer/ data system using Argon/Xenon $(6 \mathrm{kV}, 10 \mathrm{~mA})$ as the FAB gas. Accelerating voltage was $10 \mathrm{kV}$ and spectra were recorded at room temperature.

\subsection{Synthesis of Mannich base}

Semicarbazide hydrochloride $(1.11 \mathrm{~g}, 10 \mathrm{mmol})$ in $20 \mathrm{ml}$ of ethanol was neutralized with ammonia. To this solution morpholine $(0.9 \mathrm{ml}, 10 \mathrm{mmol})$ was added dropwise with constant stirring under the same condition. After $5 \mathrm{~min}$ the colourless solid obtained was filtered and recrystallized from ethanol (yield: $80 \%$; m.p. $217^{\circ} \mathrm{C}$ ).

\subsection{Synthesis of metal complexes}

A solution of $5 \mathrm{mmol}$ of $\mathrm{MCl}_{2}$ [where $\mathrm{M}=\mathrm{Cu}$ (II), $\mathrm{Ni}(\mathrm{II}), \mathrm{Co}(\mathrm{II})$ and $\mathrm{Zn}(\mathrm{II})]$ and the Mannich base $(1.25 \mathrm{~g}, 5 \mathrm{mmol})$ in ethanol and chloroform $(1: 6)$ mixture $(40 \mathrm{ml})$ was boiled under reflux for $\approx 3 \mathrm{~h}$. The resulting solution was concentrated to a third of its volume and cooled to $0^{\circ} \mathrm{C}$ for $12 \mathrm{~h}$. The precipitated complexes were filtered, washed with ethanol and dried in vacuo. The proposed structure of the complexes is given in scheme 2 .

\section{Results and discussion}

The elemental analyses show 1:2 (metal: ligand) stoichiometry for all the complexes. The analytical data of ligand and the complexes are given in table 1. They correspond well with the general formula $\mathrm{ML}_{2}$, where $\mathrm{M}=\mathrm{Cu}(\mathrm{II}), \mathrm{Ni}(\mathrm{II}), \mathrm{Co}(\mathrm{II})$ and $\mathrm{Zn}(\mathrm{II})$;
$\mathrm{L}=\left(\mathrm{C}_{12} \mathrm{H}_{18} \mathrm{~N}_{4} \mathrm{O}_{2}\right)$. The absence of chloride is evident from Volhard's test. The low conductance of the chelates supports the non-electrolytic nature of the metal complexes.

\subsection{Electronic absorption spectra}

The UV-Vis spectrum of copper complex in DMSO solution displays a broad band at $10718 \mathrm{~cm}^{-1}$ and a well-defined shoulder around $22831 \mathrm{~cm}^{-1}$, attributable to ${ }^{2} B_{1 g} \rightarrow{ }^{2} A_{1 g}$ and ${ }^{2} B_{1 g} \rightarrow{ }^{2} B_{2 g}$ transitions which strongly favour square-planar geometry around the central metal ion. ${ }^{9-11}$ The broadness of the band can be taken as an indication of distortion from perfect planar symmetry. This is further supported by the magnetic susceptibility value $(1.83 \mathrm{BM})$. The nickel complex is diamagnetic suggesting square-planar geometry. The electronic absorption spectrum of the nickel complex shows a $d-d$ band at $23077 \mathrm{~cm}^{-1}$ assigned as ${ }^{1} A_{1 g} \rightarrow{ }^{1} B_{1 g}$ transition, ${ }^{10}$ which also indicates the square planar geometry. Absence of any band below $10,000 \mathrm{~cm}^{-1}$ rules out the possibility of tetrahedral structure for this nickel chelate. The cobalt complex shows a $d-d$ band at $16216 \mathrm{~cm}^{-1}$ assigned to ${ }^{1} A_{1 g} \rightarrow{ }^{1} B_{1 g}$ transition, which confirms square-planar geometry. This is further confirmed by its magnetic susceptibility value (3.85 $\mathrm{BM})$.

\subsection{IR spectra}

In order to study the binding mode of the Mannich base to the metal ion in the complexes, the IR spectrum of the free ligand (Mannich base) was compared with the spectra of the complexes. The IR spectrum of the ligand shows bands in the regions

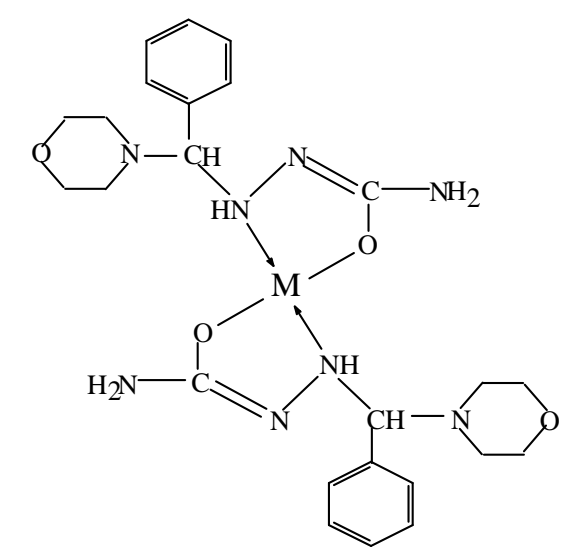

Scheme 2. The proposed structure of the complexes. 
Table 1. Physical characterization, analytical, molar conductance and magnetic susceptibility data of the complexes.

\begin{tabular}{|c|c|c|c|c|c|c|c|c|c|}
\hline \multirow{2}{*}{$\begin{array}{l}\text { Compound/ } \\
\text { complex }\end{array}$} & \multirow[b]{2}{*}{ Colour } & \multicolumn{4}{|c|}{ Found (calculated) (\%) } & \multirow{2}{*}{$\begin{array}{c}\lambda \mathrm{m} \\
\left(\mathrm{mho} \mathrm{cm}^{2}\right. \\
\left.\mathrm{mol}^{-1}\right)\end{array}$} & \multirow{2}{*}{$\begin{array}{l}\text { Mol. } \\
\text { wt. }\end{array}$} & \multirow{2}{*}{$\begin{array}{c}\text { M.p./ } \\
\text { decomp.* } \\
\left({ }^{\circ} \mathrm{C}\right)\end{array}$} & \multirow{2}{*}{$\begin{array}{c}\mu_{\text {eff. }} \\
(\mathrm{BM})\end{array}$} \\
\hline & & M & $\mathrm{C}$ & $\mathrm{H}$ & $\mathrm{N}$ & & & & \\
\hline$\left[\mathrm{C}_{12} \mathrm{H}_{18} \mathrm{~N}_{4} \mathrm{O}_{2}\right]$ & Colourless & - & $\begin{array}{c}57 \cdot 14 \\
(57 \cdot 58)\end{array}$ & $\begin{array}{c}6 \cdot 88 \\
(7 \cdot 25)\end{array}$ & $\begin{array}{c}21 \cdot 62 \\
(22 \cdot 38)\end{array}$ & - & $250 \cdot 30$ & 195 & - \\
\hline$\left[\mathrm{C}_{24} \mathrm{H}_{34} \mathrm{~N}_{8} \mathrm{O}_{4} \mathrm{Cu}\right]$ & Green & $\begin{array}{c}11 \cdot 62 \\
(11 \cdot 30)\end{array}$ & $\begin{array}{c}51 \cdot 59 \\
(51 \cdot 28)\end{array}$ & $\begin{array}{c}6 \cdot 73 \\
(6 \cdot 10)\end{array}$ & $\begin{array}{c}19 \cdot 62 \\
(19.94)\end{array}$ & 2.1 & $562 \cdot 13$ & 217 & $1 \cdot 83$ \\
\hline$\left[\mathrm{C}_{24} \mathrm{H}_{34} \mathrm{~N}_{8} \mathrm{O}_{4} \mathrm{Co}\right]$ & Pink & $\begin{array}{l}10 \cdot 73 \\
(10 \cdot 57)\end{array}$ & $\begin{array}{c}50 \cdot 91 \\
(51 \cdot 70)\end{array}$ & $\begin{array}{c}6 \cdot 01 \\
(6 \cdot 15)\end{array}$ & $\begin{array}{l}19 \cdot 87 \\
(20 \cdot 10)\end{array}$ & 1.7 & $557 \cdot 52$ & 200 & $4 \cdot 8$ \\
\hline$\left[\mathrm{C}_{24} \mathrm{H}_{34} \mathrm{~N}_{8} \mathrm{O}_{4} \mathrm{Ni}\right]$ & Pale green & $\begin{array}{c}10 \cdot 93 \\
(10 \cdot 53)\end{array}$ & $\begin{array}{c}50 \cdot 12 \\
(51 \cdot 72)\end{array}$ & $\begin{array}{c}6 \cdot 01 \\
(6 \cdot 15)\end{array}$ & $\begin{array}{l}19 \cdot 58 \\
(20 \cdot 11)\end{array}$ & 1.5 & $557 \cdot 30$ & 225 & - \\
\hline$\left[\mathrm{C}_{24} \mathrm{H}_{34} \mathrm{~N}_{8} \mathrm{O}_{4} \mathrm{Zn}\right]$ & Colourless & $\begin{array}{c}9 \cdot 02 \\
(11.59)\end{array}$ & $\begin{array}{c}51 \cdot 01 \\
(51 \cdot 11)\end{array}$ & $\begin{array}{c}5 \cdot 69 \\
(6 \cdot 08)\end{array}$ & $\begin{array}{c}19 \cdot 11 \\
(19 \cdot 87)\end{array}$ & 1.5 & 563.96 & 216 & - \\
\hline
\end{tabular}

$*$ decomp. $=$ decomposition temperature

Table 2. ${ }^{13} \mathrm{C}-\mathrm{NMR}$ spectrum of zinc complex.

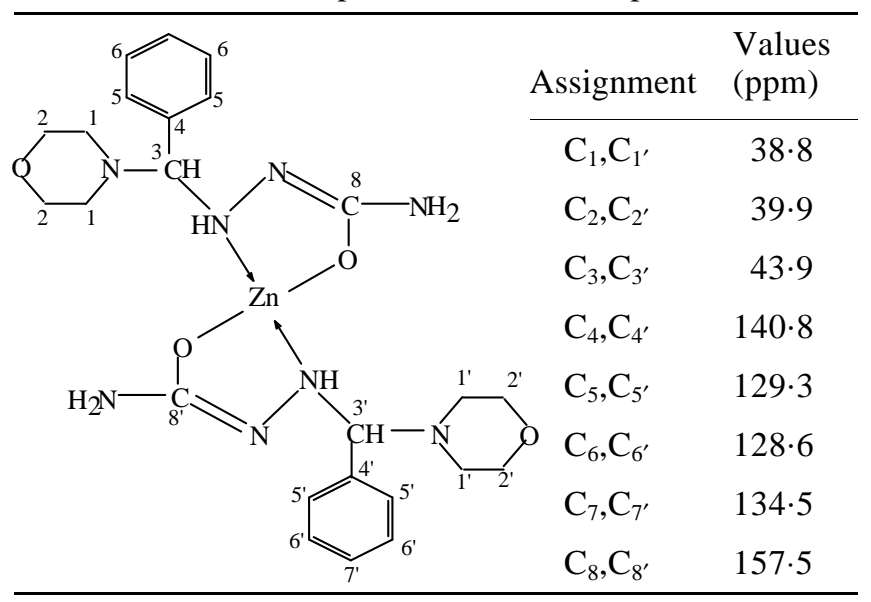

3240 and $1600 \mathrm{~cm}^{-1}$, which are assigned to $\mathrm{v}_{(\mathrm{N}-\mathrm{H})}$ and $v_{(\mathrm{C}=\mathrm{O})}$ of semicarbazone respectively. The bands due to $v_{(\mathrm{C}-\mathrm{O})}$ and $\mathrm{v}_{(\mathrm{C}=\mathrm{N})}$ are located in the regions 1135 and $1664 \mathrm{~cm}^{-1}$ respectively. ${ }^{12,13}$ In the spectra of semicarbazone complexes, the $\mathrm{v}_{(\mathrm{C}=\mathrm{O})}$ mode of the free ligand is not observed indicating the enolisation of $\mathrm{C}=\mathrm{O}$ followed by deprotonation and complexation with metal ions. The $\mathrm{v}_{(\mathrm{C}=\mathrm{N})}$ mode of ligand is found to shift to lower wave numbers suggesting the coordination of the azomethine nitrogen to the central metal ion. The band at $3240 \mathrm{~cm}^{-1}$ observed in the ligand is absent in the complexes, suggesting deprotonation of $-\mathrm{NH}$ of the ligand prior to the coordination to the metal. This is further confirmed on the basis of ${ }^{1} \mathrm{H}-\mathrm{NMR}$ studies. On the basis of this evidence, it is concluded that the ligand acts as a monobasic bidentate manner in all the complexes.

In the far-infrared region all the complexes exhibit bands around 530-470 and 460-416 $\mathrm{cm}^{-1}$ which are assignable to $\mathrm{v}_{(\mathrm{M}-\mathrm{O})}$ and $\mathrm{v}_{(\mathrm{M}-\mathrm{N})}$ modes respectively. Due to the larger dipole moment change in the vibration of $\mathrm{M}-\mathrm{O}$ band in comparison to that in the $\mathrm{M}-\mathrm{N}$ band, the band due to $\mathrm{v}_{(\mathrm{M}-\mathrm{O})}$ usually occurs in the higher frequency ${ }^{14}$ region and is usually sharp and stronger than $\mathrm{v}_{(\mathrm{M}-\mathrm{N})}$. These observations are in accordance with the structure of $M($ II) complexes with semicarbazone ligands in which the central metal ion acquires a coordination number of four.

\subsection{FAB mass spectra}

FAB mass spectrum of the ligand shows the molecular ion peak at $m / z$ 250. The copper $\left(\mathrm{C}_{24} \mathrm{H}_{34} \mathrm{~N}_{8} \mathrm{O}_{4} \mathrm{Cu}\right)$ complex shows the molecular ion peak at $m / z 562$. Both the complex and the ligand show the base peak at $m / z 164$, which is due to the fragment, $\mathrm{C}_{8} \mathrm{H}_{10} \mathrm{~N}_{3} \mathrm{O}$. The data confirm the stoichiometry of the metal complexes as being of the $\left[\mathrm{ML}_{2}\right]$ type.

\section{$3.4{ }^{1} H-N M R$ spectra}

${ }^{1} \mathrm{H}-\mathrm{NMR}$ spectra of the ligand and its zinc and nickel complexes were recorded in DMSO- $d_{6}$ solution. The ligand shows a multiplet between 7.06 and $7.88 \delta$, which is due to aromatic protons. It shows the signal at $6.7 \delta$ assigned to the $-\mathrm{CH}$ group. A broad absorption around $6 \cdot 2 \delta$ is due to the $\mathrm{NH}$ proton; morpholine $-\mathrm{N}-\mathrm{CH}_{2}$ at $2.2 \delta$ and morpholine $\mathrm{O}-\mathrm{CH}_{2}$ at $3.7 \delta$. The singlet corresponding to one proton at $10.9 \delta$ is assigned to $-\mathrm{N}=\mathrm{C}-\mathrm{OH}$ group. In the complexes, the multiplet observed in 7.18-7.20 and $7 \cdot 92-8 \cdot 10 \delta$ is due to aromatic protons. Shifting of $-\mathrm{CH}$ and $-\mathrm{NH}$ protons to the downfield confirms the involvement of azomethine nitrogen in coordina- 
Table 3. Antibacterial activities of metal (II) complexes.

\begin{tabular}{lcccccc}
\hline Compound & S. flexneri & S. typhi & P. aeruginosa & S. aureus & E. coli & K. pneumoniae \\
\hline Ampicillin & 18 & 18 & 16 & 11 & 13 & 13 \\
MBSc & 10 & - & - & - & 8 & - \\
Cu(II) complex & 22 & 14 & 17 & 15 & 18 & 16 \\
Co(II) complex & 13 & 6 & 9 & 12 & 10 & 14 \\
Ni(II) complex & 17 & 8 & 10 & 9 & 12 & 12 \\
Zn(II) complex & 23 & 12 & 17 & 12 & 18 & 13 \\
\hline
\end{tabular}

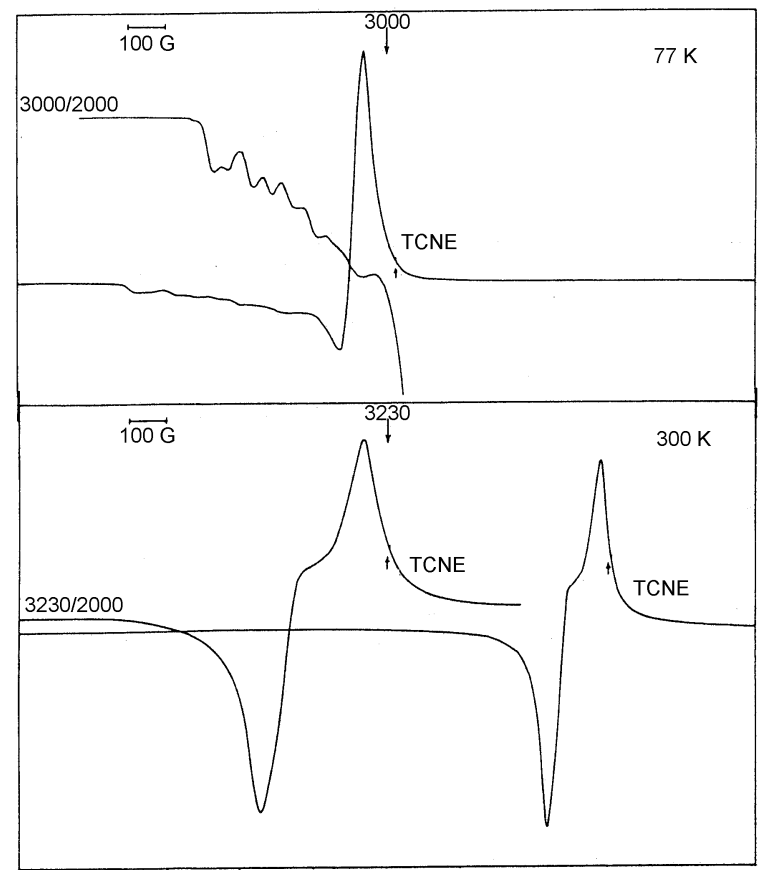

Figure 1. The X-band ESR spectrum of the copper complex, recorded in DMSO at 300 and $77 \mathrm{~K}$.

tion to the metal ion. The peak observed at $10.9 \delta$ in the ligand was absent in the complexes suggesting that the ligand is in enol form followed by coordination of carbonyl oxygen to the metal ion via deprotonation. Similarly, the ${ }^{13} \mathrm{C}-\mathrm{NMR}$ spectrum is in support of the expected signals (table 2).

\subsection{Cyclic voltammetry}

Cyclic voltammogram of the copper complex in $\mathrm{MeCN}$ solution using $\mathrm{LiClO}_{4}$ as supporting electrolyte ( 1.1 to $-1.2 \mathrm{~V}$ potential range) shows a well defined redox process corresponding to the formation of the copper(II)/copper(III) couple at $E p_{a}=0.209 \mathrm{~V}$ and the associated cathodic peak at $E p_{c}=0.155 \mathrm{~V}$. This couple is found to be reversible with $\Delta E p=$ $0.054 \mathrm{~V}$ and the ratio of cathodic to anodic peak currents $\left(I p_{c} / I p_{a} \sim 1\right)$ corresponding to a simple oneelectron process. The complex also shows a quasireversible peak in cathodic direction at $E p_{c}=-0.67 \mathrm{~V}$ which is due to the reduction of copper(II) $\rightarrow$ copper(I). In the anodic direction, the direct oxidation takes place at $E p_{a}=-0.48 \mathrm{~V}$ which is due to copper(I) $\rightarrow$ copper(II) oxidation. The reversibility of the copper(II)/copper(III) couple of the complex was unaffected by varying the scan rates ranging from 50 to $250 \mathrm{mVs}^{-1}$ with peak potentials.

\subsection{ESR spectra}

The X-band ESR spectrum of the copper complex, recorded in DMSO at 300 and $77 \mathrm{~K}$, is shown in the figure 1 . The $g$ tensor values of copper complex can be used to derive the ground state. In square planar complexes, the unpaired electron lies in the $d_{x^{2}-y^{2}}$ orbitals giving ${ }^{2} B_{1 g}$ as the ground state with $g_{11}>g_{\perp}>2$. From the observed values it is clear that $A_{11}=137>A_{\perp}=47 ; g_{11}=2.35>g_{\perp}=2.08>2$ and the ESR parameters of the complexes coincide well with related systems which suggest that the complex has square-planar geometry and the system is axially symmetric. ${ }^{15-17}$ According to Hathaway ${ }^{18} G=$ $g_{\mathrm{II}}-2 / g_{\perp}-2$; if the value of $G$ is larger than four, exchange interaction is negligible because the local tetragonal axes are misaligned. For present copper complex, the $g$ value is 4.4 , which suggests that the local tetragonal axis is aligned parallel or slightly misaligned and consistent with $d_{x^{2}-y^{2}}$ ground state.

The in-plane $\sigma$-bonding covalency parameter, $\alpha^{2}$ is found to be $0 \cdot 80$, indicates that the complex has covalent character. The out-of-plane $\pi$-bonding $\left(\gamma^{2}\right)$ and in-plane $\pi$-bonding $\left(\beta^{2}\right)$ parameters are also calculated. The observed $\beta^{2}(0.70)$ and $\gamma^{2}(1.34)$ values indicate that there is substantial interaction in the inplane bonding whereas the out-of-plane bonding is completely ionic. This is also confirmed by the values of orbital reduction factors ${ }^{19}\left(K_{\mathrm{II}}\right.$ and $\left.K_{\perp}\right)$. In the case of pure $\sigma$-bonding $K_{\mathrm{II}} \sim K_{\perp}$ implies considerable 
in-plane $\pi$-bonding while for out-of-plane $\pi$-bonding $K_{\mathrm{II}}>K_{\perp}$. For copper complexes the observed order is $K_{\text {II }}(0.56)<K_{\perp}(1.072)$ implying the presence of significant in-plane $\pi$-bonding.

\section{Conclusion}

A new Mannich base, N-(1-morpholinobenzyl) semicarbazide and its metal (II) complexes have been synthesized and characterized by elemental analyses and spectral study.

\section{Acknowledgements}

CT expresses his sincere thanks to the Tamil Nadu Government for financial assistance.

\section{References}

1. Haidue L 1990 Coord. Chem. Rev. 99253

2. Cleare M J 1974 Coord. Chem. Rev. 12349

3. Singh B, Singh R N and Aggarwal R C 1985 Polyhedron 4401
4. Mishra A P and Srivastavan S K 1994 J. Indian Council Chem. 102

5. Deshmuck M D 1995 Orent J. Chem. 11185

6. Varma R S, Rastogi N and Singh A P 2002 Indian J. Heterocyclic Chem. 12159

7. Pandit L 1995 J. Indian Council Chem. 1157

8. Pelczar M J, Chan E C S and Krieg N R 1998 Microbiology 5th edn (New York)

9. Lever A B P and Mantovani E 1971 Inorg. Chem. 10 817

10. Lever A B P 1968 Inorganic electronic spectroscopy 2nd edn (New York: Elseiver)

11. Maki G 1958 J. Chem. Phys. 28651

12. Biradar N S and Havinale B R 1976 Inorg. Chim. Acta 17157

13. Havinale B R and Pujar I B 1985 Indian J. Chem. A24 1042

14. Chkaku N and Nakamoto K 1971 Inorg. Chem. 10768

15. Ray R K and Kaufiman G B 1999 Inorg. Chim. Acta 173207

16. Antosik S, Brown N M D, Mc Connelland A A and Porte A L 1969 J. Chem. Soc. (A) 545

17. Boas J F, Dunhil R H, Pilbrow J R, Srivastava R C and Smith T D 1969 J. Chem. Soc. (A) 94

18. Hathaway B J and Tomlinson A A G 1970 Coord. Chem. Rev. 51

19. West D X 1984 Inorg. Chem. 433169 